Interação em Psicologia, 2009, 13(1), p. 69-79

\title{
Avaliando a Interação de Instruções e Comportamento Supersticioso em Esquemas Concorrentes
}

\author{
Marcelo Frota Lobato Benvenuti \\ Jéssica de Souza \\ Pontifícia Universidade Católica de São Paulo \\ Caio Flavio Miguel \\ California State University
}

\begin{abstract}
RESUMO
O objetivo do presente estudo foi avaliar a interação entre instruções e comportamento supersticioso em um componente Ext de um esquema conc VI Ext. Participantes, estudantes do ensino médio, receberam instruções corretas ou incorretas antes das sessões. Nas instruções corretas, os participantes eram informados que deveriam responder a apenas um dos componentes do esquema concorrente; nas incorretas, que deveriam responder aos dois componentes. Antes e depois das sessões eram feitas perguntas sobre o que os participantes deveriam fazer durante as sessões. Quatro dos sete participantes responderam nos componentes Ext e VI por pelo menos uma sessão. Análise das frequências mostrou que três desses quatro participantes responderam em Ext durante toda a sessão. O responder supersticioso (responder consistente em Ext) dependeu do quanto as instruções ou as contingências não verbais geraram variabilidade no responder no início das sessões.
\end{abstract}

Palavras-chave: comportamento supersticioso; instruções; esquemas concorrentes.

\section{ABSTRACT \\ Evaluating the Interaction Among Instructions and Superstitious Behavior in Concurrent Schedules}

\begin{abstract}
The purpose of the current study was to evaluate the interaction between instructions and "superstitious" behavior in an Ext component of a conc VI Ext schedule. Participants, high-school students, received correct or incorrect instructions at the beginning of the sessions. Correct instructions consisted of telling the participants that they should respond to only one component of the schedule; incorrect instructions consisted of telling the participants to respond to both components of the schedule. After and before the sessions, participants received questions that asked what they would need to do during sessions. Four of the seven participants responded both in Ext and in VI components of concurrent schedule at last in one session. Analysis of frequencies of responses in Ext components showed that three of these four participants responded during the whole session. Superstitious behavior (responding in Ext component) depended on variability generated by instructions or by non-verbal contingencies at the beginning of the sessions.
\end{abstract}

Keywords: superstitious behavior; instruction; concurrent schedules.

Pessoas eventualmente agem como se estivessem produzindo mudanças no ambiente que na verdade não estão. Podem agir sem saber que o fazem ou podem descrever o que fazem: às vezes falando algo que é oposto ao que fazem; às vezes descrevendo relações entre ação e ambiente que na verdade não existem. Contribuindo para explicar por que isso acontece, a Análise do Comportamento tem produzindo um crescente número de estudos que investigam como o comportamento pode ser afetado por relações de proximi- dade entre ações e mudanças no ambiente e como isso pode estar relacionado com o comportamento verbal.

Em um experimento publicado em 1948, Skinner mostrou que o comportamento de pombos poderia ser afetado por apresentações de alimento que ocorriam independentemente de seus comportamentos (Skinner, 1948). Apesar de independente, a apresentação do alimento poderia ocorrer contígua a certas respostas, fortalecendo acidentalmente o responder e fazendo com que o organismo respondesse como se estivesse 
produzindo consequências que na verdade não dependiam de suas ações. $\mathrm{O}$ efeito da relação acidental do responder com reforço ficou conhecido, na Análise do Comportamento, como comportamento supersticioso.

No comportamento humano uma grande quantidade de repertórios importantes e sofisticados é adquirida sem contato direto com contingências de reforço, por meio de descrição de contingências. Descrições de contingências podem controlar o comportamento como antecedentes verbais que estabelecem a ocasião na qual respostas, se emitidas, podem ser reforçadas. Comportamento controlado por antecedentes verbais tem sido chamado de comportamento governado por regras (Skinner, 1969) ou controlado verbalmente (Catania, 1998).

Respostas inicialmente controladas por descrição de contingências podem ser mantidas por relação acidental com reforço. Higgins, Morris e Johnson (1989) examinaram essa possibilidade fornecendo, a crianças, instruções que sugeriam uma relação de dependência entre respostas e mudanças que na verdade não existia: depois de instruídas de que podiam receber bolinhas de gude por meio de respostas ao nariz de um palhaço, as crianças eram expostas a uma situação em que as bolinhas eram apresentadas independentemente do responder, de acordo com um esquema múltiplo de tempo variável e extinção. As crianças começavam as sessões respondendo aos dois componentes do esquema múltiplo e, ao final de quinze sessões, mantinham-se respondendo apenas no componente de tempo variável.

Eventualmente, o próprio comportamento verbal pode ser "supersticioso": uma relação de contiguidade entre resposta e mudança ambiental pode ser descrita verbalmente como uma relação de dependência. Esse é o caso do resultado obtido por Heltzer e Vyse (1994). Os autores expuseram estudantes a uma tarefa experimental em que oito respostas deveriam ser distribuídas em duas chaves de respostas. Não importava como os participantes alocavam suas respostas, consequências eram apresentadas de acordo com os esquemas de Razão Fixa 1 ou 2 ou Razão Randômica 2 (FR 2, FR 1 ou RR 2). Durante as condições, especialmente em RR 2, os participantes diziam que certas sequências eram mais efetivas para a produção da consequência do que outras. A descrição verbal da situação, formulada pelos próprios participantes, sugeria uma relação entre respostas e mudanças ambientais que na verdade não correspondia às programadas no experimento.

Resultados experimentais como os de Heltzer e Vyse têm fortalecido a noção de que superstições, no comportamento humano, podem ser interpretadas como "falsas regras" (Ono, 1994) ou "crenças supersticiosas" (Heltzer \& Vyse, 1994) ou ainda "regras supersticiosas" (Heltzer \& Vyse, 1994; Ninnes \& Ninnes, 1998, 1999). Cabe, contudo, perguntar sobre o papel das "crenças supersticiosas" na determinação do comportamento em estudos como o de Heltzer e Vyse. Descrições "supersticiosas" de contingências, na forma de instruções ou autodescrições, seriam estímulos discriminativos que facilitariam o comportamento "supersticioso" (como em Higgins \& cols., 1989) ou seriam apenas comportamento verbal sob controle do próprio desempenho não verbal do participante?

Raramente a relação ente comportamento supersticioso e formulação de "regras supersticiosas" é avaliada explicitamente. Apesar disso, alguns estudos recentes têm avaliado o efeito de relações de contiguidade para a produção de comportamento supersticioso a partir do relato verbal dos participantes: por avaliações, realizadas a partir de escalas, do quanto o participante julga ter controle sobre uma situação de apresentação de eventos independentes do responder (Aeschleman, Rosen \& Williams, 2003; Bloom, Venard, Harden \& Seetharaman, 2007). O uso do relato verbal para avaliar o comportamento supersticioso sugere, implicitamente, que há uma relação direta entre o fazer e o dizer, o que não é necessariamente observado em estudos que investigaram a relação entre o que as pessoas fazem em uma determinada tarefa experimental e o que dizem que fazem na tarefa (ver, por exemplo, Catania, Matthews \& Shimoff, 1982; Torgrud \& Holborn, 1990).

Para determinar a interação entre comportamento verbal e comportamento supersticioso, são importantes delineamentos que permitam a comparação do comportamento não verbal com o verbal, em especial para verificar o papel do comportamento verbal em facilitar o comportamento supersticioso na forma de descrições de contingências fornecidas pelo experimentador ou formuladas pelo próprio participante. Benvenuti, Panetta, da Hora e Ferrari (2008) avaliaram o papel de instruções que sugerem relações de dependência entre resposta e consequência sobre o desempenho em uma situação semelhante à utilizada por Higgins e cols. (1989). Depois de instruídos (instruções mínimas ou instruções que sugeriam uma relação de dependência entre respostas e mudanças ambientais), os participantes eram expostos a uma situação em que pontos eram apresentados independentes do responder de acordo com um esquema múltiplo em que alternavam-se períodos em que pontos eram apresentados em média a cada oito segundos (VT $8 \mathrm{~s}$ ), com períodos em que os pontos não eram 
apresentados (Ext). Em três experimentos, cerca de metade dos 16 participantes apresentou comportamentos supersticiosos, responder consistente no componente VT acompanhado de redução do responder em Ext em pelo menos uma sessão.

No estudo de Benvenuti e cols. (2008), o desenvolvimento do supersticioso, contudo, parece ter dependido das contingências não verbais (esquema complexo) mais do que das instruções dadas no início de cada sessão: comportamento supersticioso apareceu em condições de instrução mínima, bem como em condições de instruções mais ou menos explícitas que sugeriam a relação de dependência entre repostas e mudanças ambientais. Análise de relatos coletados ao fim das sessões mostrou que os participantes apresentaram "relatos supersticiosos" quando apresentavam comportamento supersticioso, sugerindo que os relatos poderiam ser vistos como produto das mesmas contingências que geraram o responder supersticioso, não como determinantes do responder mantido por relação acidental com reforço. Os "relatos supersticiosos" foram caracterizados como tatos sob controle do desempenho supersticioso. A mesma relação entre "relatos supersticiosos" e comportamento supersticioso foi observada em um estudo realizado por Panetta, da Hora e Benvenuti (2008), com esquemas simples, em que, a depender da condição experimental, pontos eram apresentados independentemente do responder.Tomados em conjunto, os resultados de Benvenuti e cols. (2008) e Panetta e cols. (2008) sugerem um uso mais cuidadoso de expressões como "regras supersticiosas" ou mesmo "regras falsas", especialmente quando as descrições verbais são produzidas pelos próprios participantes. As descrições podem ser relatos verbais sob controle do desempenho do próprio participante. Seriam, portanto, descrições "corretas", sob controle de um desempenho supersticioso.

Os estudos apresentados até o momento servem para mostrar que a relação entre "regra supersticiosa" e comportamento supersticioso ainda não é clara. $\mathrm{O}$ controle exercido por uma descrição em que se sugere incorretamente que há contingência entre resposta e ambiente parece depender de aspectos dos procedimentos que têm sido utilizados para avaliação do comportamento supersticioso.

Frequentemente, comportamento supersticioso é produzido em esquemas em que são programadas mudanças ambientais independentes do responder do participante. Catania e Cutts (1963), contudo, planejaram uma situação experimental em que o comportamento mantido por relação acidental com reforço foi produzido em uma situação em que reforço foi dependente do responder. Catania e Cutts, em um trabalho com estudantes universitários, programaram um es- quema concorrente, situação em que duas chaves de respostas estavam simultaneamente disponíveis aos participantes, operando simultaneamente a partir de contingências diferentes. Respostas a uma chave nunca eram reforçadas enquanto respostas à outra chave eram reforçadas de acordo com um esquema de intervalo variável a cada $30 \mathrm{~s}$, em média (conc VI Ext). Responder supersticioso se mantinha porque pressões à chave de extinção eram seguidas de reforço contingente ao responder subsequente em VI para a maior parte dos participantes - comportamento chamado de superstição topográfica por Ono (1994), porque parte da topografia da resposta que produz o reforço é selecionado por relação acidental com reforço. O procedimento de atraso no reforço para a mudança do responder de uma chave para a outra preveniu ou eliminou o responder supersticioso. Ao final das sessões os participantes falavam a respeito do que faziam, em geral descrevendo seus próprios desempenhos, supersticiosos ou não.

O presente estudo tem como objetivo avaliar a aquisição e a manutenção de comportamentos supersticiosos e o efeito de descrições de contingências que sugerem erroneamente relações de dependência entre respostas e mudanças ambientais em uma situação de reforço dependente do responder. A avaliação pode fornecer dados importantes para a discussão da generalidade das conclusões alcançadas por Benvenuti e cols. (2008) e Panetta e cols. (2008) a respeito do papel das descrições ou autodescrições "supersticiosas".

A proposta do presente estudo foi avaliar a interação de instruções/autorrelatos e o comportamento supersticioso produzido no componente Ext em um esquema conc VI Ext. Uma das vantagens do uso do esquema dependente para avaliação do efeito de instruções ou do autorrelato sobre o responder supersticioso é que se torna possível diminuir, embora não eliminar, a variabilidade no responder que pode ser selecionada pelo reforço acidental. No esquema múltiplo utilizado por Benvenuti e cols. (2008), a variabilidade no responder pode envolver qualquer resposta do participante. Diferentemente, no esquema concorrente, a variabilidade no responder é reduzida, pois o reforço torna frequente uma determinada topografia de resposta - clicar com o mouse para responder ao esquema VI -, aumentando a chance de que clicar seja a resposta selecionada acidentalmente no componente Ext do esquema concorrente. Com a redução da variabilidade possível de ser selecionada acidentalmente torna-se mais fácil avaliar o efeito da apresentação de descrições de contingências sobre o comportamento supersticioso. Um aspecto interessante adicional do esquema conc VI Ext é que a manutenção do 
responder em VI (dependente) fornece uma base de comparação para avaliar se o padrão de respostas no componente em extinção pode ser caracterizado como supersticioso.

\section{MÉTODO}

\section{Participantes}

Participaram do experimento sete estudantes do ensino médio, com idades entre 15 e 18 anos. Todos os participantes, antes do início da coleta de dados, foram informados que o trabalho envolveria uma atividade no computador e seria feito para avaliar as hipóteses que fariam enquanto realizavam a tarefa. Pais dos participantes assinaram Termo de Consentimento Livre e Esclarecido aprovado pelo Comitê de Ética em Pesquisa da PUC-SP.

\section{Local e Equipamento de Coleta}

Os dados foram coletados na casa de um dos experimentadores, em uma sala em que os participantes podiam trabalhar sem serem interrompidos. As contingências experimentais foram programadas por software na linguagem Visual Basic. O programa rodava em um laptop utilizado para a coleta dos dados. Os participantes trabalhavam sozinhos na sala de coletas enquanto o experimentador esperava em outra sala. Antes de iniciada a sessão e ao seu final, os participantes eram instruídos pelo pesquisador a responder perguntas em um questionário.

\section{Instruções Gerais e Tarefa Experimental}

Quando o participante entrava pela primeira vez na sala experimental, o experimentador lia a seguinte Instrução Geral:

Esta atividade da qual você participa não visa medir a sua inteligência ou a sua personalidade. É apenas uma atividade para estudo das possíveis relações entre uma tarefa feita no computador e as hipóteses que você venha a formular enquanto trabalha nessa atividade. Não há, portanto respostas certas e erradas. Você precisará de 2 a 10 sessões de, aproximadamente, 7 minutos cada para concluir seu trabalho. Você deverá construir uma figura na tela manipulando o mouse, podendo clicar em dois retângulos coloridos. Clicando nos retângulos você poderá ganhar pedaços da figura e pontos. Para formar a figura não adianta clicar fora dos retângulos.

Os participantes também recebiam instruções escritas na tela do computador antes de iniciada a sessão. A primeira tela do computador continha a seguinte instrução: "Este jogo é um QUEBRA-CABE-
ÇAS. O seu objetivo é formar uma figura que está oculta". No canto inferior direito da tela o participante podia clicar em "Avançar", passando para a segunda tela, onde se lia: "Para formar a figura, você deverá CLICAR o MOUSE sobre os RETÂNGULOS COLORIDOS que aparecerão na tela". Mais uma vez clicando em "avançar", o participante recebia a terceira tela, em que estava escrito: "Pronto para começar? BOA SORTE!".

Clicando em "avançar" mais uma vez, iniciava-se a tarefa experimental. O participante poderia clicar, com o mouse, um de dois retângulos coloridos que apareciam na tela do computador, do lado esquerdo. Pedaços de uma figura, pontos e um som de palmas eram apresentados simultaneamente. A "figura oculta" era composta de 80 pedaços e a tarefa terminava quando a figura estivesse completa. A Figura 1 mostra o monitor do computador em três momentos da tarefa experimental: no início, quando a tarefa se iniciava depois das instruções; ao meio, quando a figura de um barco já está incompleta; e ao final, quando a figura do barco está toda montada no monitor do computador. Além da figura do barco, outras figuras podiam ser montadas: a figura de um gato, de um cisne, de uma flor e de uma árvore.
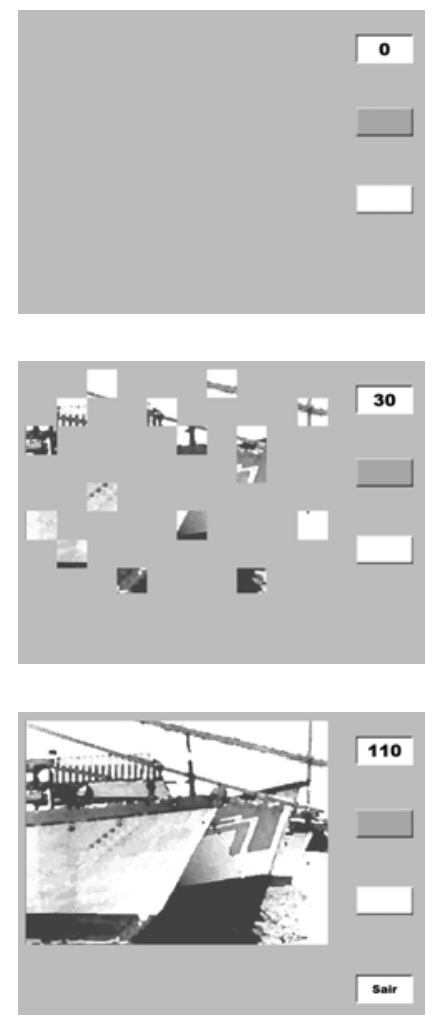

Figura 1. Monitor do computador em três diferentes momentos da sessão experimental. 
Pedaços da figura, pontos e o som das palmas eram apresentados de acordo com o esquema conc VI Ext. Respostas a um dos retângulos coloridos produziam as consequências de acordo com o esquema VI $8 \mathrm{~s}$, enquanto respostas ao outro retângulo estavam em extinção. Respostas aos retângulos eram automaticamente registradas a cada um segundo e os dados da sessão ficavam gravados no computador. $\mathrm{O}$ som de palmas tinha a duração de $1,5 \mathrm{~ms}$., tempo durante o qual os retângulos de respostas ficavam desabilitados.

\section{Procedimento}

Após a Instrução Geral, os participantes foram submetidos às duas condições experimentais descritas a seguir ou somente à segunda delas.

1. Condição de Instrução Correta: Aparecia na tela do computador a seguinte instrução antes que o participante tivesse acesso à tarefa:

Na tela seguinte, você encontrará dois retângulos nos quais poderá clicar o mouse, um retângulo amarelo e outro azul. Você precisa clicar em apenas um dos retângulos para construir a figura e ganhar os pontos. Com esta pesquisa estamos querendo avaliar as hipóteses que você formula enquanto trabalha nessa atividade. Antes de começar a trabalhar queremos saber o seu palpite: em qual dos retângulos você acha que deverá clicar para construir a figura e ganhar pontos?

Logo depois de ouvir a instrução, o participante recebia uma caneta e uma folha com a seguinte questão: "Dê seu palpite". Após responder, era iniciada a tarefa experimental propriamente dita, na qual o sujeito lia instruções na tela e chegava à etapa de montar o "quebra cabeça". No retângulo azul, superior, estava em vigor o esquema VI; no retângulo amarelo, abaixo do azul, vigorava extinção.

A Condição de Instrução Correta era encerrada quando o participante terminava uma sessão tendo emitido $80 \%$ do total de respostas de clicar o mouse no componente VI. A condição também foi encerrada caso o participante permanecesse sem atingir o critério de encerramento por cinco sessões. Nesse último caso, o participante não participava da condição seguinte.

Na segunda sessão e nas demais da mesma condição, o participante não ouvia mais a instrução geral. Antes da sessão ser iniciada aparecia na tela do computador a seguinte instrução:

$\mathrm{Na}$ tela seguinte você encontrará novamente dois retângulos nos quais poderá clicar o mouse, um retângulo amarelo e outro azul. Lembre-se de que você precisa clicar em apenas um dos retângulos para construir a figura e ganhar os pontos. Mais uma vez, antes de come- çar a trabalhar queremos saber o seu palpite: em qual dos retângulos você acha que deverá clicar para construir a figura e ganhar pontos?

O procedimento para coleta do palpite era o mesmo da primeira sessão.

2. Condição Instrução Incorreta: Nesta condição, a instrução apresentada ao participante antes do início da tarefa experimental foi a seguinte:

$\mathrm{Na}$ tela seguinte você encontrará dois retângulos, um amarelo e outro azul, nos quais poderá clicar o mouse para formar a figura. Há uma sequência correta de cliques entre os dois retângulos que você precisará descobrir para construir a figura e ganhar os pontos. Nesta fase também queremos saber o seu palpite: qual a sequência necessária de cliques entre os dois retângulos que você acha que é a correta para formar a figura?

A tarefa experimental e as demais condições de registro de relato eram as mesmas da condição anterior.

Quatro participantes foram submetidos à Condição de Instrução Correta e três à Condição de Instrução Incorreta. Dos quatro participantes que passaram pela Condição de Instrução Correta, três passaram também, posteriormente, pela Condição de Instrução Incorreta, pois atingiram o critério de mudança.

A Tabela 1 mostra o número de sessões a que cada participante foi submetido.

TABELA 1

Participantes e Número de Sessões em cada Condição Experimental, Condição de Instrução Correta e Incorreta

\begin{tabular}{ccc}
\hline & \multicolumn{2}{c}{ Número de Sessões } \\
\cline { 2 - 3 } Participantes & Instrução correta & Instrução incorreta \\
\hline BZ & 3 & 2 \\
MP & 5 & - \\
LB & 4 & 1 \\
CM & 1 & 1 \\
AT & - & 1 \\
FB & - & 1 \\
BR & - & 4 \\
\hline
\end{tabular}

A posição, cor e a contingência que operava em cada um dos retângulos coloridos não foram alteradas ao longo das sessões experimentais.

Coleta de Relatos Verbais Pós-sessão: Além dos palpites, também foram coletados relatos pós-sessão para análise da descrição do participante sobre o que havia acontecido na sessão experimental. Após cada sessão, o participante respondia por escrito sobre o que fazia na sessão e sobre o que acontecia na sessão. 


\section{RESULTADOS}

No procedimento utilizado no presente estudo, responder sistemático em Ext indica a manutenção do responder neste componente por relação acidental com reforço dependente de respostas no componente VI. Um aspecto interessante adicional do procedimento utilizado é que a manutenção do responder em VI fornece uma base de comparação para o obtido no componente em extinção e permite ainda avaliar o valor reforçador das consequências utilizadas no experimento.

A Figura 2 mostra a taxa de respostas nos componentes VI e Ext do esquema concorrente nas sessões dos participantes MP, BZ, LB e CM. Esses participantes receberam a instrução correta antes da instrução incorreta. Marcadores abertos indicam a curva de respostas no componente extinção e marcadores escuros indicam respostas no componente VI do esquema concorrente. Dados antes da linha pontilhada correspondem aos obtidos na Condição de Instrução Correta; depois da linha pontilhada, correspondem aos obtidos com a introdução da instrução incorreta.

Uma comparação da taxa de respostas em VI com a taxa em Ext do esquema concorrente mostra padrões diferenciados entre os participantes e que variaram ao longo das sessões. No primeiro gráfico da figura, à esquerda, podemos observar que MP apresentou praticamente as mesmas taxas de respostas nos componentes VI e extinção das sessões a que foi submetido.
A taxa variou eventualmente entre sessões, mas muito pouco na mesma sessão. MP não atingiu o critério para mudança de condição e terminou o experimento depois de cinco sessões da primeira condição. No gráfico abaixo ao de MP, vemos que BZ apresentou taxas de respostas parecidas nos dois componentes apenas nas primeiras sessões da Condição de Instrução Correta. A taxa nos componentes em extinção foi bem menor do que em VI na última sessão da condição, ou seja, o participante concentrou o maior número de respostas em VI, o que permitiu a passagem para a condição seguinte. Na Condição de Instrução Incorreta, BZ apresentou taxas semelhantes em VI e em Ext na primeira sessão apenas; na sessão seguinte, a taxa de respostas em Ext chegou próxima de zero, enquanto em VI aumentou consideravelmente. No gráfico do canto direito superior, que representa o padrão de LB, é possível notar que este participante apresentou responder equivalente em VI e em Ext nas primeiras sessões, mas deixou de responder em Ext na última sessão da primeira condição e na primeira sessão da Condição de Instrução Incorreta. O último gráfico da figura, canto inferior à direita, mostra o desempenho de CM, que foi submetido a apenas duas sessões, uma da Condição de Instrução Correta e a outra da Condição de Instrução Incorreta. Nas duas sessões, uma da Condição de Instrução Correta e outra Condição de Instrução Incorreta, a taxa de respostas em Ext foi bem menor do que em VI, estando próximas de zero.

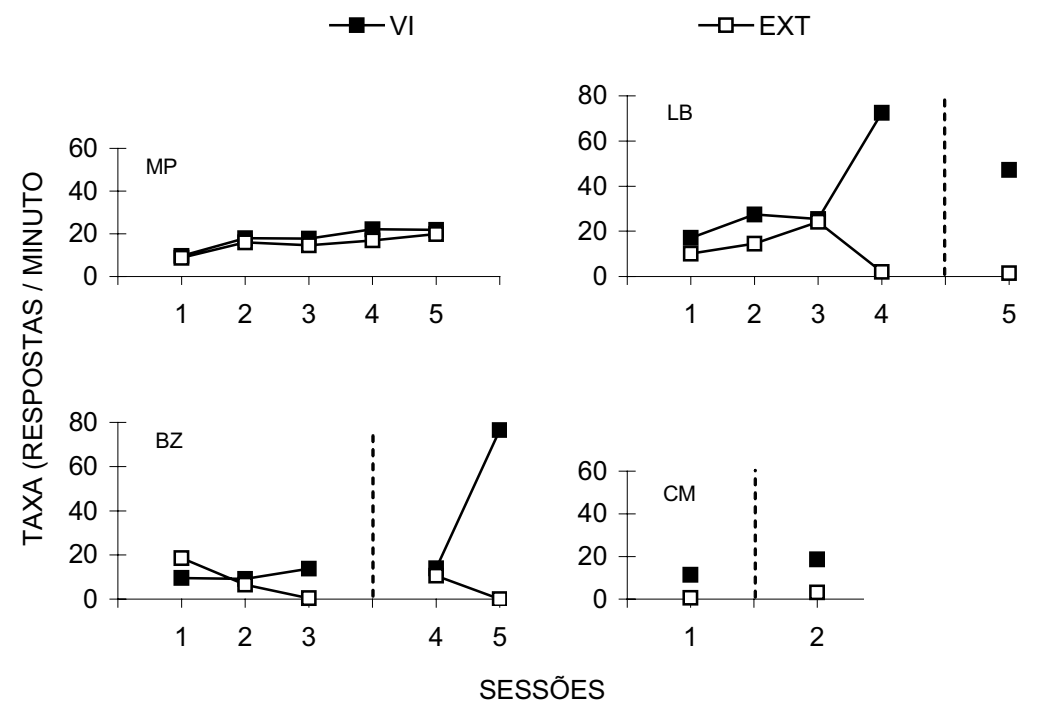

Figura 2. Taxa de respostas nos componentes VI e Ext do esquema concorrente nas sessões dos participantes que receberam a instrução correta antes da instrução incorreta. Marcadores abertos indicam a curva de respostas no componente extinção e marcadores escuros indicam respostas no componente VI do esquema concorrente. Dados antes da linha pontilhada correspondem aos obtidos na condição de instrução correta; depois da linha pontilhada, correspondem aos obtidos com a introdução da instrução incorreta. 
Na Figura 3, vemos as taxas de respostas em VI e Ext dos participantes que receberam apenas a instrução incorreta antes da realização das sessões. AT e FB participaram apenas de uma sessão: os dois primeiros gráficos da figura mostram que esses dois participantes respondem quase exclusivamente em VI, apresentando em Ext taxas próximas a zero. BR, cujo desempenho é representado no último gráfico, apresentou taxas parecidas em VI e em Ext ao logo das sessões. Nas duas primeiras sessões, as taxas foram praticamente as mesmas; nas duas últimas sessões as taxas diferenciaram-se porque aumentou a taxa de respostas no componente VI. A taxa no componente Ext continuou praticamente a mesma ao longo das quatro sessões.

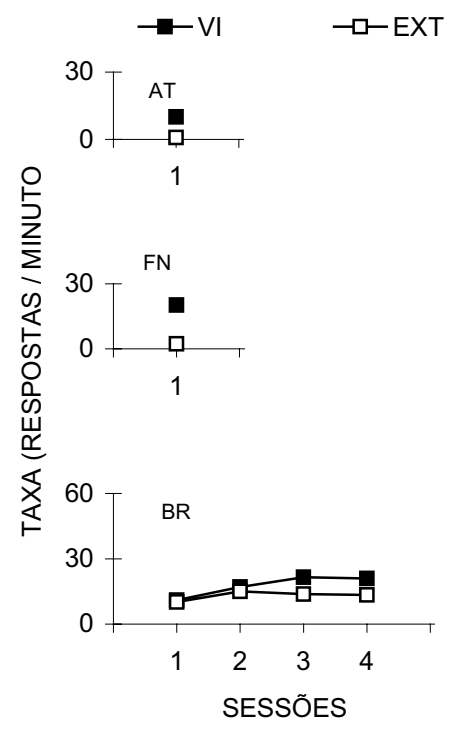

Figura 3. Taxa de respostas nos componentes VI e Ext do esquema concorrente nas sessões dos participantes que receberam apenas a instrução incorreta.
A análise da frequência de respostas nos componentes em extinção do esquema concorrente fornece detalhes adicionais sobre o desempenho dos participantes e sobre a mudança de padrão ao longo das sessões. A Figura 4 mostra curvas de respostas acumuladas apenas no componente Ext para cada participante ao longo das sessões realizadas. Cada curva corresponde à frequência acumulada em uma sessão. Os dados são organizados como na Figura 1, para facilitar a comparação das taxas em VI e em Ext com a frequência acumulada em Ext. $\mathrm{O}$ primeiro gráfico à direita mostra a frequência de respostas em Ext de MP. MP respondeu em todas as sessões em Ext com frequência constante. No gráfico abaixo, à esquerda, vemos o padrão de $\mathrm{BZ}$ em extinção. Os dados acumulados da primeira sessão foram perdidos, mas, na segunda sessão, BZ apresentou um padrão de responder / pausa, seguido de uma terceira sessão em que BZ quase não respondeu em extinção. $\mathrm{O}$ mesmo padrão responder / pausa, pode ser identificado na passagem de condição, quando BZ recebeu a instrução incorreta. $\mathrm{Na}$ segunda sessão da condição incorreta, mais uma vez BZ deixou de responder em extinção.

Nas curvas de extinção de LB, que aparecem no terceiro gráfico, canto superior à direita, podemos observar uma frequência de resposta razoavelmente constante em Ext apenas nas três primeiras sessões. Nas outras curvas, a frequência de resposta em extinção foi marcada por pausas e acelerações. Para CM, último gráfico à esquerda, também pode ser observado um ligeiro aumento na frequência de respostas na segunda sessão, quando o participante mudou para a condição de instrução incorreta. Do segundo terço da sessão para o final, a curva de extinção de CM mostra uma pausa no responder.

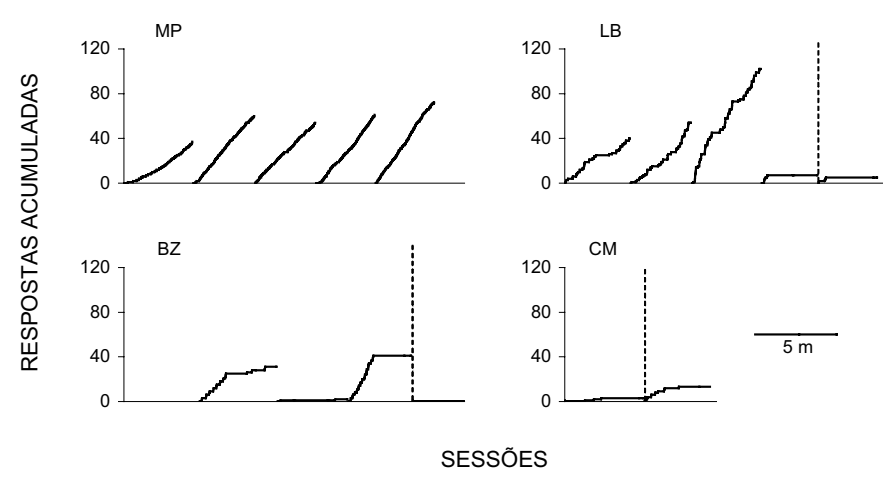

Figura 4. Frequência acumulada de respostas no componente Ext do esquema concorrente para os participantes que foram expostos à Condição de Instrução Correta e à Condição de Instrução Incorreta. Cada curva acumulada corresponde a uma sessão da condição. Linha pontilhada separa os resultados de cada uma das condições. 
Na Figura 5, são apresentados os padrões de extinção dos participantes que receberam apenas a instrução incorreta. Para AT e FB, a frequência é baixa, havendo algumas poucas acelerações ocasionais em alguns pontos específicos da sessão. No último gráfico da figura, vemos o desempenho de BR, que respondeu com frequência estável no componente extinção do esquema concorrente em todas as sessões.

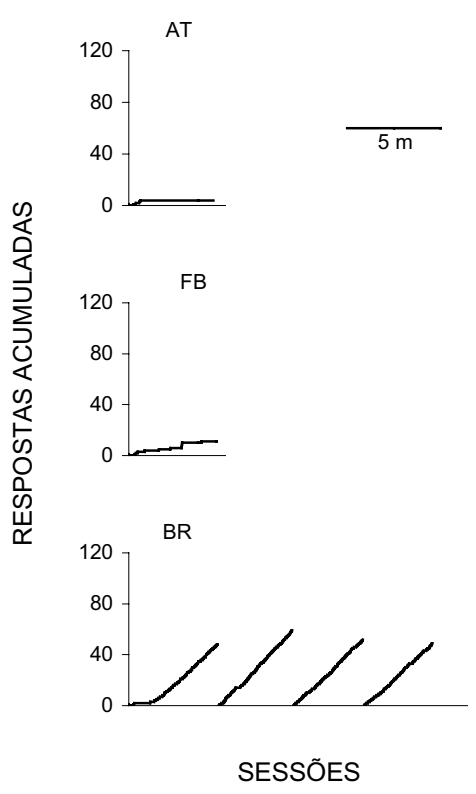

Figura 5. Frequência acumulada de respostas no componente Ext do esquema concorrente para os participantes que foram expostos apenas à Condição de Instrução Incorreta. Cada curva acumulada corresponde a uma sessão da condição.

Na Tabela 2 são apresentados os "palpites" de cada participante em relação ao que deveriam fazer para ganhar os pontos. Os palpites são comparados com o componente em que o participante emitiu a primeira resposta da sessão e o padrão da curva de extinção, que foi classificada como: a) responder constante, quando a curva mostra respostas distribuídas ao longo de toda a sessão; b) resposta / pausa, quando a curva mostra aceleração constante no início da sessão (pelo menos no primeiro terço da sessão), seguida de pausa; c) pausa, quando não há respostas em extinção, ou quando uma aceleração ocasional não chega a ocupar pelo menos um terço da sessão.
TABELA 2

Palpites, Componente em que Foi Emitida a Primeira Resposta da Sessão e Padrão da Curva de Extinção (A - Responder Constante; B - Resposta Pausa; C - Pausa) em Cada Sessão Experimental dos Participantes do Experimento

\begin{tabular}{|c|c|c|c|c|}
\hline & Sessão & Palpites & $\begin{array}{l}\text { Primeira } \\
\text { Resposta }\end{array}$ & $\begin{array}{l}\text { Padrão } \\
\text { Extinção }\end{array}$ \\
\hline \multirow[t]{5}{*}{$\mathrm{MP}$} & 1 & $\mathrm{VI}$ & $\mathrm{VI}$ & $A$ \\
\hline & 2 & VI & VI & $A$ \\
\hline & 3 & EXT & EXT & $A$ \\
\hline & 4 & VI & VI & $A$ \\
\hline & 5 & $\mathrm{VI}$ & $\mathrm{VI}$ & A \\
\hline \multirow[t]{5}{*}{$\mathrm{BZ}$} & 1 & EXT & EXT & -- \\
\hline & 2 & EXT & VI & $B$ \\
\hline & 3 & VI & VI & C \\
\hline & 4 & VI/EXT & EXT & B \\
\hline & 5 & $\mathrm{VI}$ & $\mathrm{VI}$ & $C$ \\
\hline \multirow[t]{5}{*}{ LB } & 1 & EXT & EXT & $A$ \\
\hline & 2 & EXT & EXT & A \\
\hline & 3 & VI & $\mathrm{VI}$ & A \\
\hline & 4 & VI & VI & C \\
\hline & 5 & EXT & $\mathrm{Vl}$ & C \\
\hline \multirow[t]{2}{*}{$\mathrm{CM}$} & 1 & $\mathrm{VI}$ & $\mathrm{VI}$ & $C$ \\
\hline & 2 & EXT & EXT & $\mathrm{B}$ \\
\hline AT & 1 & $\mathrm{VI}$ & $\mathrm{VI}$ & $C$ \\
\hline FB & 1 & VI/EXT & $\mathrm{VI}$ & C \\
\hline \multirow[t]{4}{*}{$\mathrm{BR}$} & 1 & $\mathrm{VI}$ & $\mathrm{VI}$ & $A$ \\
\hline & 2 & EXT & EXT & $A$ \\
\hline & 3 & VI & $\mathrm{VI}$ & A \\
\hline & 4 & $\mathrm{VI}$ & VI & $A$ \\
\hline
\end{tabular}

Analisando a Tabela 2, é possível notar que eventualmente a primeira resposta do participante não esteve de acordo com o seu palpite: é o caso da segunda sessão de BZ, a última sessão de LB e a única sessão de FB. Em alguns casos, podemos observar a relação entre responder em extinção (pelo menos no início da sessão) e o palpite ou a primeira resposta do participante. Há, contudo, muitos padrões diferentes, sendo difícil concluir sobre um padrão geral. Para MP e BR, os dois participantes que responderam com frequência constante em Ext em todas as sessões, há palpites em VI e Ext tanto quanto primeiras respostas em ambos os componentes.

Ao relatar o que acontecia nas sessões, ao final, os participantes em geral descreveram o próprio desempenho: "tinha que clicar no lugar certo, uma certa quantidade de vezes e depois clicar em outro mais ou menos cinco vezes no azul e uma vez no amarelo" (BZ, Sessão 1, Condição de Instrução Correta); "comecei pelo azul e vi que clicando nele não acontecia 
nada, então parti pro amarelo. E só nele é que eu ganhava os pontos e ia fazendo a figura. Se eu jogasse de novo, já começaria pelo amarelo, agora que já sei que só clicando nele os quadrados aparecem" (CM, Sessão 1, Condição de Instrução Incorreta).

Muitas vezes, os participantes apresentaram relatos sem menção ao que faziam especificamente em cada um dos retângulos: "tive a mesma pontuação que da primeira vez. Ainda não consegui pegar a sequência. Fica confuso, porque eu tento descobrir, mas já se foram vários cliques" (BR, Sessão 1, Condição de Instrução Incorreta).

\section{DISCUSSÃO}

Quatro dos sete participantes (MP, LB, BZ e BR) apresentaram taxas no componente Ext próximas às apresentadas em VI. A comparação das taxas em Ext com as frequências mostrou que taxas altas significaram na maior parte das vezes responder constante em Ext ao longo das sessões para MP, LB e BR. Esses três participantes apresentaram frequências de respostas constantes em Ext em mais de uma sessão, enquanto BZ apresentou frequência alta em Ext no início de algumas das sessões e pausa do meio para o final. MP e BR continuaram a responder no componente Ext ao longo das sessões realizadas; LB deixou de fazê-lo depois de três sessões.

Responder consistente no componente Ext pode ser explicado por reforço acidental: reforço produzido por responder em VI mantinha não só o responder neste componente como também no componente em Ext. Assim, responder em Ext pode ser considerado comportamento supersticioso. MP e LB apresentaram responder consistente em Ext mesmo nas condições de instrução correta, em que o participante lia uma instrução que dizia que ele deveria responder apenas em um dos retângulos.

O objetivo do estudo foi avaliar a interação entre comportamento verbal e a produção de comportamento supersticioso no componente Ext de um esquema conc VI Ext. Diferente do estudo de Higgins e Morris (1989), o comportamento verbal não apareceu no presente estudo apenas na forma de instruções. Como no estudo de Benvenuti e cols. (2008) e no de Panetta e cols. (2008), também foi investigado o papel de autorrelatos sobre o que deveria ser feito na sessão, de modo a aproximar a presente análise com a feita por Heltzer e Vyse (1994) a respeito do papel de "regras supersticiosas". A coleta dos "palpites" também possibilitou uma análise adicional sobre o controle verbal gerado nos participantes pelas instruções fornecidas no início de cada sessão.

A análise da resposta ao palpite mostra algumas possibilidades do tipo de controle verbal que a instrução pode ter exercido sobre os participantes. LB, por exemplo, afirmou no palpite que deveria responder no componente Ext nas duas primeiras sessões e respondeu de acordo. LB apresentou comportamento supersticioso ao longo das três primeiras sessões das quais participou. AT, que foi exposta à condição de instrução incorreta, deu o palpite de que deveria responder no componente VI, respondendo de acordo e continuando a responder em VI ao longo das sessões. Note-se que, embora a contingência descrita na instrução fosse "responda a dois retângulos", aparentemente o controle verbal gerado em AT pela instrução foi "responda a um dos retângulos".

Com exceção de BR, a instrução fornecida aos participantes não pareceu facilitar o surgimento de comportamento supersticioso. Dos três participantes que apresentaram responder consistente em Ext, dois deles (MP e LB) o fizeram na Condição de Instrução Correta. Dos três participantes que receberam apenas a instrução incorreta, apenas para um (BR) houve responder consistente em Ext. E possível que para os participantes expostos às duas condições, a história promovida com a Condição de Instrução Correta tenha influenciado o desempenho mais geral na Condição de Instrução Incorreta. Apesar disso, o maior controle para o surgimento de comportamento supersticioso não parece estar nas instruções fornecidas aos participantes nem no comportamento verbal gerado nos participantes durantes a exposição às tarefas sejam palpites ou autodescrições. Como nos estudos de Benvenuti e cols. (2008) e Panetta e cols. (2008), o comportamento supersticioso parece ter dependido mais das contingências não verbais do que propriamente do comportamento verbal.

Os resultados do presente estudo podem ser considerados como uma demonstração adicional de comportamento supersticioso, evidência da possibilidade de seleção acidental do responder em função de relações de contiguidade entre respostas e mudanças ambientais (Skinner, 1948). Os resultados replicam a observação de comportamento supersticioso em esquemas complexos, como já havia sido demonstrado em esquemas concorrentes (Catania \& Cutts, 1963) e múltiplos (Higgins, Morris \& Jonhson, 1989). A demonstração adicional em esquemas concorrentes, "superstição topográfica", é especialmente importante porque mostra que o responder supersticioso pode 
aparecer em situações de reforço dependente. O esquema concorrente, nesse sentido, seria responsável por uma contingência $\mathrm{S}-\mathrm{S}$, que depende de como o responder do sujeito produz modificações que funcionam como reforçadores. Os reforçadores, por sua vez, podem relaciona-se por contiguidade com outras respostas que não aquelas que foram responsáveis pelo seu aparecimento.

A literatura da área tem permitido diferenciar aquisição de manutenção "supersticiosa", dependendo do momento em que entra em vigor a contingência S-S responsável pelo responder supersticioso (Neuringer, 1970; Weisberg \& Kennedy, 1969). O estudo de Higgins e col. (1989) traz implícita a diferenciação entre aquisição e manutenção "supersticiosa", uma vez que as crianças emitiram respostas sob controle de instruções e, emitindo as primeiras respostas, era possível a seleção acidental do comportamento por eventos apresentados independentemente do responder. No estudo de Higgins e cols., instruções tinham papel na aquisição; reforço acidental, na manutenção.

Os resultados encontrados pela presente investigação e por Benvenuti e cols. e Panetta e cols. permitem retomar a discussão levantada por Higgins e col. sobre o papel de variáveis culturais na produção do comportamento supersticioso. Além do que foi descrito na Introdução do presente trabalho, Higgins e col. trabalharam com um grupo controle no qual as crianças não recebiam instruções e eram submetidas ao mult VT Ext. Essas crianças não apresentaram responder supersticioso, indicando o papel da instrução incorreta para que o supersticioso surgisse no comportamento das crianças dos outros grupos. Outras crianças, de outro grupo experimental, adquiriram comportamento supersticioso quando expostas ao mult VT Ext depois de terem observado outras, por meio de um vídeo, respondendo "supersticiosamente". Instrução e modelação seriam para Higgins e cols. duas condições típicas da cultura que poderiam facilitar comportamento supersticioso. Os presentes resultados sugerem fortemente que mais do que instruções ou modelação, o importante para a produção do comportamento supersticioso são as relações de contiguidade e contingências presentes nas relações operantes envolvidas na situação. Instruções, por exemplo, parecem ser efetivas na produção de comportamento supersticioso à medida que promovem o surgimento de variabilidade comportamental, que pode, então, ser selecionada pelo reforço. O mesmo pode ser dito das próprias contingências não verbais: o comportamento supersticioso parece depender de como as condições de es- quemas múltiplos ou concorrentes geram variação comportamental em uma ou outra direção.

Vale a pena ainda discutir que o que está sendo chamado de resposta do participante é aquela registrada pelo experimentador. A instrução incorreta ou o esquema concorrente seriam formas de facilitar certa resposta do participante que pode ser identificada e registrada pelo experimentador. Nesse sentido, as conclusões do presente estudo são semelhantes às de Neuringer (1970), que sugeriu que o comportamento supersticioso no repertório geral dos organismos é muito mais frequente do que se imagina. Para o estudo experimental do comportamento supersticioso o que parece ter maior importância é que no início do estudo seja garantido que apareça uma resposta discreta e fácil de registrar. Em estudos do papel do autorrelato, a definição de uma resposta discreta e fácil de ser identificada é uma vantagem extra, pois é fácil de ser observada pelo próprio participante (e pode, portanto, gerar controle sobre seu comportamento verbal). No caso específico dos esquemas concorrentes, o participante pode desenvolver sequências de respostas que são fáceis de serem observadas e registradas, tanto pelo experimentador como por ele próprio, quando for relatar seu comportamento.

\section{REFERÊNCIAS}

Aeschleman, S. R., Rosen, C. C., \& Williams, R. R. (2003). The effect of non-contingent negative and positive reinforcement operations on the acquisition of superstitious behavior. Behavioural Processes, 61, 37-45.

Benvenuti, M. F. L., Panetta, P. B., da Hora, C. L., \& Ferrari, S. (2008). Comportamento "supersticioso" em esquemas múltiplos: Efeitos de instruções e auto-descrições. Interação em Psicologia, 12, 35-50.

Bloom, C. M., Venard, J., Harden, M., \& Seetharaman, S. (2007). Non-contingent positive and negative reinforcement schedules of superstitious behavior. Behavioural Processes, 75, 8-13.

Catania, A. C. (1998). Learning ( $4^{\mathrm{a}}$ ed.). New Jersey: PrenticeHall.

Catania, A. C., \& Cutts, D. (1963). Experimental control of superstitious responding in humans. Journal of the Experimental Analysis of Behavior, 6, 203-208.

Catania, A. C., Matthews, B. A., \& Shimoff, E. (1982). Instructed versus shaped human verbal behavior: Interactions with nonverbal responding. Journal of the Experimental Analysis of Behavior, 38, 233-248.

Heltzer, R. A., \& Vyse, S. A. (1994). Intermittent consequences and problem solving: The experimental control of "superstitious" beliefs. The Psychological Record, 44, 155-169.

Higgins, S. T., Morris, E. K., \& Johnson, L. M. (1989). Social transmission of superstitious behavior in preschool children. The Psychological Record, 39, 307-323. 
Neuringer, A. J. (1970). Superstitious key pecking after three peck-produced reinforcements. Journal of the Experimental Analysis of Behavior, 13, 127-134.

Ninnes, H. A., \& Ninnes, S. K. (1998). Superstitious math performance interactions between rules and schedule contingencies. The Psychological Record, 48, 45-62.

Ninness, H. A., \& Ninness, S. K. (1999). Contingencies of superstition: Self generated rules and responding during second-order response-independent schedules. The Psychological Record, 49, 221-243.

Ono, K. (1994). Verbal control of superstitious behavior: Superstitions as false rules. Em S. C. Hayes, L. J. Hayes, M. Sato \& $\mathrm{K}$. Ono (Orgs.), Behavior analysis of language and cognition (pp. 181-196). Reno, NV: Context Press.

Panetta, P. B., da Hora, C. L., \& Benvenuti, M. F. L. (2008). Avaliando o papel do comportamento verbal para aquisição de comportamento "supersticioso". Revista Brasileira de Terapia Comportamental e Cognitiva, 9, 121-131.

Skinner, B. F. (1948). Superstition in the pigeon. Journal of Experimental Psychology, 38, 168-172.

Skinner, B. F. (1969). Contingencies of reinforcement: A theoretical analysis. New York: Appleton-Century-Crofts.

Torgrud, L. J., \& Holborn, S. W. (1990). The effects of verbal performance descriptions on nonverbal operant responding. Journal of the Experimental Analysis of Behavior, 54, 273-291.

Weisberg, P., \& Kennedy, D. B. (1969). Maintenance of children's behavior by accidental schedules of reinforcement. Journal of the Experimental Child Psychology, 8, 222-233.

Recebido: 06/03/2008

Última revisão: 12/05/2009

Aceite final: 20/05/2009

Nota:

${ }^{1}$ A coleta de dados foi realizada com bolsa de Iniciação Científica CEPE-PUC para a segunda autora (processo 04-1131). O trabalho faz parte da linha de pesquisa "Avaliando a interação entre regras e comportamento mantido por relação acidental com reforço", desenvolvida no Laboratório de Psicologia Experimental da PUC-SP. Os autores agradecem à Cacilda Amorim pelo desenvolvimento do software utilizado neste estudo e à Danielle LaFrance pelos comentários na primeira versão do trabalho.

\section{Sobre os autores:}

Marcelo Frota Lobato Benvenuti: Doutor em Psicologia Experimental pela Universidade de São Paulo. Professor da Pontifícia Universidade Católica de São Paulo. Atualmente, professor convidado na Universidade de Brasília e bolsista PRODOC/CAPES.

Jéssica de Souza: Graduada em Psicologia pela Pontifícia Universidade Católica de São Paulo. Bolsista CEPE-PUC IC durante a graduação.

Caio Flavio Miguel: Doutor em Psicologia pela Western Michigan University. Professor na California State University.

Endereço para correspondência: Marcelo Frota Lobato Benvenuti - SQS 106, Bloco E, apto. 106 - 70345-050 Brasília/DF - Endereço eletrônico:mbenvenuti@yahoo.com. 